\title{
Preventive Cardiology
}

\section{Random Fasting Hyperglycemia as Cardiovascular Risk Factor in the Elderly: A 6-Year Longitudinal Study}

\author{
Roberto Antoniceldi, M.D., Rosaria Gesuita, Ph.D., * Massimo Boemi, M.D., $\dagger$ Enrico Paciaroni, M.D., for the Camerano \\ STUDY Group
}

Divisione di Patologia Cardiovascolare ed Ipertensione Arteriosa, I.N.R.C.A. (Italian National Research Centre on Aging); *Centro Interdipartimentale di Epidemiologia, Biostatistica e Informatica Medica, Università degli Studi di Ancona; tReparto di Diabetologia (Italian National Research Centre on Aging), Ancona, Italy

\begin{abstract}
Summary: A large body of evidence suggests that diabetes increases the risk of coronary heart disease (CHD), but whether fasting hyperglycemia is associated with a major risk for CHD is still under debate. The aim of the present study was to investigate the role played by fasting hyperglycemia in the development of cardiovascular disease (CVD) in an elderly population when associated with common risk factors for CVD (i.e., hypertension, hypercholesterolemia, smoking, etc). We analyzed a sample of 455 subjects aged $\geq 60$ years. The risk factors taken into account were systolic and diastolic blood pressure levels, use of antihypertensive drugs, total serum cholesterol, serum triglycerides, and smoking habit. Glycemia was measured at entry on a fasting sample. During the follow-up period (mean 6 years), the occurrence of CVD was monitored (criteria for the occurrence of CVD included total cardiovascular mortality, fatal or nonfatal myocardial infarction, symptomatic coronary heart disease [stable and unstable angina], the need for percutaneous transluminal coronary angioplasty or coronary artery bypass graft, fatal or nonfatal stroke, and transient ischemic attack). A total of 427 subjects completed the follow-up. During this period, 73 subjects (17.10\%) developed CVD according to the above criteria. A Cox proportional hazard model was designed to evaluate the contribution of variables in predicting CVD. Relative risks
\end{abstract}

\section{Address for reprints:}

Dott. R. Antonicelli

Dipartimento di Patologia Cardiovascolare ed Ipertensione Arteriosa INRCA

Via Della Montagnola 164

60100 , Ancona, Italy

Received: April 3. 2000

Accepted with revision: August 15. 2000 and $95 \%$ confidence intervals for CVD were calculated from the regression coefficients to study the association between the risk of developing CVD and predicting variables. We found a relation between occurrence of CVD and fasting hyperglycemia: subjects with fasting glycemia, $>126 \mathrm{mg} / \mathrm{dl}$ at enrollment, but without previous clinical diagnosis of diabetes, showed a 2.01 times higher risk than those with fasting glycemia $<126 \mathrm{mg} / \mathrm{dl}$. Hence, random fasting hyperglycemia can predict the occurrence of CVD in elderly subjects.

Key words: hyperglycemia, aging, hypertension, cholesterol, longitudinal study

\section{Introduction}

Diabetes is associated with increased mortality from coronary heart disease (CHD) and stroke. ${ }^{1-4} \mathrm{~A}$ similar association is found in nondiabetic subjects with raised blood glucose levels indicative of glucose intolerance, but below diagnostic cutoff level for diabetes. ${ }^{5}$ Important studies have shown that fasting hyperglycemia and lipid levels predict the occurrence of diabetic complications and related mortality. ${ }^{6-9}$

The role of random fasting hyperglycemia in the development of cardiovascular disease (CVD) in elderly subjects is even less known, mainly because of a paucity of studies taking into account this parameter together with established CHD risk factors (i.e., smoking, blood lipids, blood pressure, age, and obesity). Stamler and Stamler showed that glucose levels are related to CHD risk, but whether this effect is linear or threshold is unclear. ${ }^{9}$

In the elderly population dyslipidemia, hypertension, smoking habit, and obesity play a controversial role in the development of CVD. Some observational studies suggest that hypercholesterolemia can contribute to increasing the risk of CVD in the elderly population, ${ }^{10-12}$ while other stud- 
ies have failed to find any association between cholesterol and cardiovascular events in patients aged $>70$ years. ${ }^{13-15}$ The power of serum cholesterol as a CVD predictor seems to decline with age. ${ }^{16}$

Some studies have reported that hypertension is a predictor of CVD in the elderly, ${ }^{17-19}$ but even low blood pressure levels are associated with a reduced survival in very old patients. ${ }^{20-22}$ It was shown that the risk for CVD related to smoking appears to diminish with advancing age in some ${ }^{17,18,23}$ but not all studies. ${ }^{18,24}$

The present 6-year follow-up study was conducted in an unselected population and it investigates the relationship between random fasting glucose levels and CVD.

\section{Methods}

Between 1990 and 1996, a medical survey on CVD and aging was performed in Camerano, a small town in Central Italy that was chosen for its own characteristic homogeneity from both a genetic (minimal migratory flow during the last 60 years) and an environmental (traditional lifestyle and diet) point of view.

A random sample of 515 subjects aged $\geq 60$ years (representing $>50 \%$ of the resident, noninstitutionalized elderly population) was examined. These subjects were chosen from the registry data given by the town council. The sampling procedure guaranteed random criteria and selected a stratified sample according to gender and age.

At the first visit, a complete medical history was recorded and informed consent was obtained. Thereafter, patients ( $\mathrm{n}$ $=60$ ) who already suffered from diabetes or CVD (myocardial infarction, angina, heart failure, etc.) were excluded at follow-up. Follow-up visits were scheduled every 3 years.

Blood pressure was measured by a mercury sphygmomanometer, using the auscultatory method after a 5-min rest in sitting position. ${ }^{25-27}$ The mean of three readings was used to identify the subjects as normotensive (systolic blood pressure $[\mathrm{SBP}]<140 \mathrm{mmHg}$ and diastolic blood pressure [DBP] $<90 \mathrm{mmHg}$ ), or hypertensive (SBP $>140$ and/or DBP $>90 \mathrm{mmHg}$, as well as those subjects taking antihypertensive medication).

Total plasma cholesterol and triglycerides were measured by enzymatic standard procedure; glycemia was measured by enzymatic hexokinase-glucose-6-phosphate dehydrogenase method (Dade Behring, Inc., Deerfield, Ill., USA).

Classification of patients as hyperglycemic was revised according to the new guidelines for the diagnosis of diabetes used in the United States, with cut-off values for impaired fasting glucose at 110 and $125 \mathrm{mg} / \mathrm{dl}$. A cut-off value of 126 $\mathrm{mg} / \mathrm{dl}$ was used to classify subjects as hyperglycemic. ${ }^{28}$

During the follow-up period (median 6 years) the occurrence of CVD was monitored in all patients.

A cardiovascular event was defined as the first CVD event including total cardiovascular mortality, fatal or nonfatal myocardial infarction, symptomatic coronary heart disease (stable and unstable angina), the need for percutaneous translumi- nal coronary angioplasty or coronary artery bypass graft, fatal or nonfatal stroke, and transient ischemic attack. Only clinically documented events were taken into account.

\section{Statistical Analysis}

Occurrence of CVD was analyzed according to risk factor variables: continuous variables were compared using the Student's $t$-test; the chi-square test was performed for categorical variables.

A Cox proportional hazard model was designed to evaluate the contribution of variables in predicting CVD. Relative risks and $95 \%$ confidence intervals for CVD were calculated from the regression coefficients in order to study the association between the risk of developing cardiovascular heart disease and predicting variables. A level of $5 \%$ was used to assess statistical significance. The SAS system (SAS, Cary, N.C., USA) was used for all analyses.

\section{Results}

In all, 455 nondiabetic subjects aged $\geq 60$ years were enrolled in the Camerano Study on Cardiovascular Risk Factors in 1990. Only 427 subjects concluded the follow-up, since 28 subjects $(6.2 \%)$ refused to participate in follow-up control visits. During the follow-up period, 73 subjects (17.1\%) developed CVD, 15 of these had a fatal event, and 24 subjects died of other causes. Moreover, 23 subjects (5.3\%) developed diabetes according to the World Health Organization (WHO) criteria. ${ }^{29}$ The median time of followup was 6 years for all subjects; the median time free of CVD was 3 years for those who developed a CVD.

In the univariate analysis, subjects with CVD were older and had a higher SBP than those who did not develop CVD; in this latter group, frequency of high fasting glycemia was significantly lower (Table I). The two groups did not differ with regard to gender, diastolic blood pressure level, smoking habit, use of antihypertensive drugs, serum cholesterol, and triglycerides concentration.

All variables were then included in the Cox proportional hazard model (Table II). An important marker of occurrence of CVD was hyperglycemia: subjects with high levels of fasting glycemia had a risk 2.01 times greater than those with levels of glycemia below the cut-off value of $126 \mathrm{mg} / \mathrm{dl}$.

In our study, all subjects with impaired fasting glucose (110-125 mg/dl) showed no significant increase of the risk of cardiovascular event.

A second significant variable in the model was age: older subjects were more likely to develop CVD and the relative risk for a change at 1 year was 1.10. Relative risks for the other variables did not reach the statistical significance.

\section{Discussion}

Diabetic patients as well as patients with glucose tolerance in the upper part of the normal range have increased cardiovas- 
TABLE I Cross-tabulation of cardiovascular disease and risk factors

\begin{tabular}{lccc}
\hline Variables & CVD present & CVDabsent & p Value \\
\hline Number & 73 & 354 & $<0.00 !^{\prime \prime}$ \\
Age [years, mean (SD)] & $71.6(5.8)$ & $67.6(5.6)$ & $0.697^{b}$ \\
Sex [male, $\mathrm{n}(\%)]$ & $32(43.8)$ & $164(46.3)$ & $0.0025^{a}$ \\
Systolic blood pressure [mmHg, mean (SD)] & $155.5(22.4)$ & $147.4(20.2)$ & $0.405^{\prime \prime}$ \\
Diastolic blood pressure [mmHg, mean (SD)] & $88.8(11.0)$ & $87.7(10.3)$ & $0.496^{b}$ \\
Blood pressure medication [n $(\%)]$ & $28(38.4)$ & $121(34.2)$ & $0.898^{b}$ \\
Smoking [n $(\%)]$ & $24(36.9)$ & $118(36.1)$ & $0.231^{b}$ \\
Cholesterol $>200 \mathrm{mg} / \mathrm{dl}[\mathrm{n}(\%)]$ & $38(63.3)$ & $226(71.1)$ & $0.757^{b}$ \\
Triglycerides $>200 \mathrm{mg} / \mathrm{dl}[\mathrm{n}(\%)]$ & $10(16.7)$ & $48(15.1)$ & $0.004^{b}$ \\
Glycemia $>126 \mathrm{mg} / \mathrm{dl}[\mathrm{n}(\%)]$ & $16(26.7)$ & $39(12.3)$ & \\
\hline
\end{tabular}

"Student's $t$-test.

${ }^{b}$ Chi-square test.

cular morbidity and mortality. ${ }^{1-4}$ Whether CHD risk increases with higher fasting glucose concentrations in subjects without diabetes is controversial.

Recent reports show an increase in the number of deaths from stroke and from CHD among patients ranging in age from 45 to 74 years; ${ }^{30}$ accordingly, our data show a relationship between aging and risk of CVD (Table I).

Table I shows that higher SBP is associated with occurrence of CVD. This is in agreement with previously reported data showing a link between blood pressure levels, both systolic and diastolic, and risk of stroke and cardiovascular events. ${ }^{3 !}$

Moreover in the diabetic population from the United Kingdom Prospective Diabetes (UKPD) study, a significant reduction of the risk of stroke and of cardiovascular events could be achieved by a tight control of blood pressure levels. ${ }^{32}$

We did not observe a relationship between cholesterol and triglycerides levels and CVD. The fact that we could not measure HDL and LDL cholesterol can explain this result.

In the UKPD study, fasting hyperglycemia appears to play an important role in the development of CVD, together with other significant risk factors such as low high-density lipopro-

TABLE II Results of Cox proportional hazard model for occurrence of coronary heart disease

\begin{tabular}{lccc}
\hline Predictors & Odds ratio & $95 \% \mathrm{Cl}$ & p Value \\
\hline Age & 1.11 & $1.05-1.16$ & $<0.001$ \\
Sex (M/F) & 1.16 & $0.52-2.59$ & NS \\
Systolic blood pressure & 1.00 & $0.99-1.02$ & NS \\
Diastolic blood pressure & 1.00 & $0.97-1.04$ & NS \\
Blood pressure medication & & & \\
$\quad$ Yes/No) & 1.02 & $0.56-1.87$ & NS \\
Cholesterol $(>200 \mathrm{mg} / \mathrm{dl})$ & 1.04 & $0.59-1.84$ & $\mathrm{NS}$ \\
Triglygerides $(>200 \mathrm{mg} / \mathrm{dl})$ & 1.38 & $0.67-2.81$ & $\mathrm{NS}$ \\
Glycemia $(>126 \mathrm{mg} / \mathrm{dl})$ & 2.01 & $1.07-3.76$ & 0.030 \\
Smoking $($ Yes/No) & 1.44 & $0.65-3.20$ & $\mathrm{NS}$ \\
\hline
\end{tabular}

Abbreviations: $\mathrm{NS}=$ not significant, $\mathrm{M}=$ male, $\mathrm{F}=$ female, $\mathrm{CI}=\mathrm{con}$ fidence interval. tein concentration, elevated low-density lipoprotein concentration, HBAlc, elevated blood pressure, cigarette smoking, and age. ${ }^{33}$

In the Camerano elderly population, random fasting hyperglycemia proved to be a major determinant for death from CVD. A random fasting glycemia $>126 \mathrm{mg} / \mathrm{dl}$ levels was associated with a two-fold increase in the risk for CVD.

Our findings are in accordance with those of Barret-Connor et al., who demonstrated a positive association between fasting plasma glucose and mortality from $\mathrm{CHD},{ }^{6}$ and with those of Balkau et al. who showed a relation between fasting hyperglycemia and mortality from CHD in middle-aged, nondiabetic men. ${ }^{34}$

Moreover, based on evidence on the linkage between fasting hyperglycemia and the risk of CVD, the American Diabetes Association Expert Committee suggested the introduction of a new category in the diagnosis and classification of diabetes: the impaired fasting glycemia (IFG) ${ }^{28}$

\section{Conclusion}

The evaluation of cardiovascular risk in the elderly cannot simply rely on the common factors due to the physiologic changes occurring during aging. Disturbances of glucose metabolism, that is, a reduction of glucose tolerance. can contribute to the development of CVD.

Thus, periodic measurements of fasting glycemia are recommended in elderly persons to evaluate glucose metaboli$\mathrm{sm}$. In subjects with moderate alteration of fasting glycemia, no evidence at present supports the hypothesis of a pharmacologic intervention, but it is reasonable to consider the possibility of dietary modification to reduce the potential cardiovascular risk.

\section{Camerano Study Group}

Dott. F. Ferroni, Dott. R. Carlini, Dott.ssa L. Pascali, Dott. R. Taccaliti, Dott. E. Manfrin, W.J.F. Fitzpatrick, Dott. A. Camilletti, Dott.ssa L. Amadio. 


\section{References}

1. Donahue RP, Orchard TJ: Diabetes mellitus and macrovascular complications: An epidemiological perspective. Diabetes Care 1992:15:1141-1155

2. Eschwege E, Richard JL, Thibult N, Ducimitiere P, Warnet JM, Claude JR, Rosselin GE: Coronary heart disease mortality in relation with diabetes, blood glucose and plasma insulin levels. The Paris Prospective Study, ten years later. Horm Metab Res (suppl) $1985 ; 15: 41-46$

3. Butler WJ, Ostrander LD Jr, Carman WJ, Lamphiear D: Mortality from coronary heart disease in the Tecumseh study. Long-term effect of diabetes mellitus, glucose tolerance and other risk factors. Am J Epidemiol 1985;121(4):541-547

4. Fuller JH, Shipley MJ, Rose G, Jarret RJ, Keen H: Mortality from coronary heart disease and stroke in relation to degree of glycaemia: The Whitehall study. Br Med J (Clin Res Ed). 1983;24;287 (6396):867-870

5. Eschwege E, Balkau B, Fontbonne A: The epidemiology of coronary heart disease in glucose-intolerant and diabetic subjects. J Intern Med (suppl). 1994;736:5-1 1

6. Barret-Connor E, Wingard DL, Criqui MH, Suarez L: Is borderline fasting hyperglycemia a risk factor for cardiovascular death? JChron Dis 1984;37:773-779

7. Stamler R, Stamler J: Asymptomatic hyperglycemia and coronary heart disease: A series of papers by the International Collaborative Group based on studies in 15 populations: Joint discussion. J Chmn Dis 1979;32:829-837

8. Cruz-Vidal M, Garcia-Palmieri MR, Costas R, Sorlie PD, Havlik $\mathrm{RJ}$ : Abnormal blood glucose and coronary heart disease: The Puerto Rico Heart Health Program. Diabetes Care 1983;6(6):556-561

9. Stamler R, Stamler J: Asymptomatic hyperglycemia and coronary heart disease in middle-aged men in two employed populations in Chicago. J Chron Dis 1979;32(11-12):805-815

10. Rubin SM, Sidney S, Black DM, Browner WS, Hulley SB, Cummings SR: High blood cholesterol in elderly man and the excess risk for coronary heart disease. Ann Intern Med 1990; 1 13:916-920

11. Manolio TA, Pearson TA, Wenger NK, Barret-Connors E, Payne $\mathrm{GH}$, Harlan WR: Cholesterol and heart disease in older persons and women. Review of NHLBI workshop. Ann Epidemiol 1991;2: $161-176$

12. Kannel WB: Range of serum cholesterol values in the population developing coronary artery disease. Am J Cardiol 1995;28,76(9): $69 \mathrm{C}-77 \mathrm{C}$

13. Benfante R, Reed D: Is elevated serum cholesterol level a risk factor for coronary heart disease in the elderly? J Am Med Assoc 1990; 263:393-397

14. Castelli WP, Wilson PW, Levy D, Anderson K: Cardiovascular risk factors in the elderly. Am J Cardiol 1989;63(suppl): $12 \mathrm{H}-19 \mathrm{H}$

15. Krumholz HM, Seeman TE, Merril SS, Mendes de Leon CF, Vaccarino V, Silverman DI, Tsukahara R, Ostfeld AM, Berkman LF: Lack of association between cholesterol and coronary heart disease mortality and morbility and all-cause mortality in persons older than 70 years. J Am Med Assoc 1994;272:1335-1349

16. Law MR, Wald NJ, Thompson G: By how much and how quickly does reduction in serum cholesterol concentration lower risk of ischaemic heart disease. BrMed J 1994;308:367-370
17. Harris T, Cook ES, Kannel WB, Goldman L: Proportional hazard analysis of risk factors for coronary heart disease in individuals aged 65 and older: The Framingham Heart Study. J Am Geriatric Soc 1988;36: 1023-1028

18. Cullen K, Stenhouse NS, Wearne KL, Welborn TA: Multiple regression analysis of risk factor for cardiovascular disease and cancer mortality in Busselton: 13 years study. J Chron Dis 1983;36: 371-377

19. Aronow WS, Herzing AH, Etienne F: 41-months follow-up of risk factors correlated with new coronary events in 708 elderly patients. JAm Geriatric Soc 1989;37:501-506

20. Mattila K, Haavisto M, Rajala S, Heikinheimo R: Blood pressure and survival in very old. $B r$ Med $J$ 1988;296:887-891

21. Langer RD, Ganiats TG, Barret-Connor EL: Paradoxical survival of elderly men with high blood pressure. $\mathrm{Br}$ Med $J$ 1989;298: 1356-1361

22. Benfante $R$, Reed D: Is elevated serum cholesterol level a risk factor for coronary heart disease in the elderly? J Am Med Assoc 1990;263:393-397

23. D'Agostino RB, Belanger AJ, Kannel WB, Higgins M: Role of smoking in the U-shaped relation of cholesterol to mortality in men. The Framingham Study. Am J Epidemiol 1995;141(9):822-827

24. Jajich CL, Ostfeld AM, Freeman DH: Smoking and coronary heart disease mortality in the elderly. J Am Med Assoc 1984;308:367-371

25. Antonicelli R, Gesuita R, Zingaretti P, Amadio L, Pagelli P, Cusi D, Paciaroni E: Camerano study on hypertension: The problem of blood pressure variability during medical visit. Clin Exper Hypertens 1993;15:125-138

26. Antonicelli R, Gesuita R, Amadio L, Ursini T, Paciaroni E: Camerano study on hypertension: Association between arterial hypertension and cardiovascular risk factors. Clin Exper Hypertens 1993; 15:98-112

27. Antonicelli R, Gesuita R, Amadio L, Paciaroni E: Camerano study on hypertension: The problem of arterial hypertension in the elderly. Arch Gent Ger 1992;12(suppl. 3): 17-26

28. Report of the Expert Committee on the Diagnosis and Classification of Diabetes Mellitus. Diabetes Care 1997;20, 7:1 183-1197

29. World Health Organization: Diabetes Mellitus: Report of WHO Study Group. Geneva: World Health Org., 1985 (Tech. Rep. Ser., no. 727)

30. World Health Organization: World Health Statistics Annual. Geneva: World Health Organization, 1995

31. World Health Organization-International Society of Hypertension: Guidelines for the management of hypertension. $J$ Hypertens 1999,17:151-183

32. UK Prospective Diabetes Study Group: Tight blood pressure control and risk of macrovascular and microvascular complications in type 2 diabetes: UKPDS 38. BrMed J 1998,317:703-720

33. Stratton I, Manley S, Holman R, Turner R: Hypertension in Diabetes Study IV: Therapeutic requirements to maintain high blood pressure control. Diabetologia 1996;39:1554-1561

34. Balkau B, Shipley M, Jarret R, Piorala K, Piorala M, Forhan M, Eschwege $\mathrm{E}$ : High blood glucose concentration is a risk factor for mortality in middle-aged nondiabetic men. Diabetes Care 1998;21 (3):360-367 